\title{
||||||||||||||||||||||||||||||||||||||||||||||||||||||||||||||||||.
}

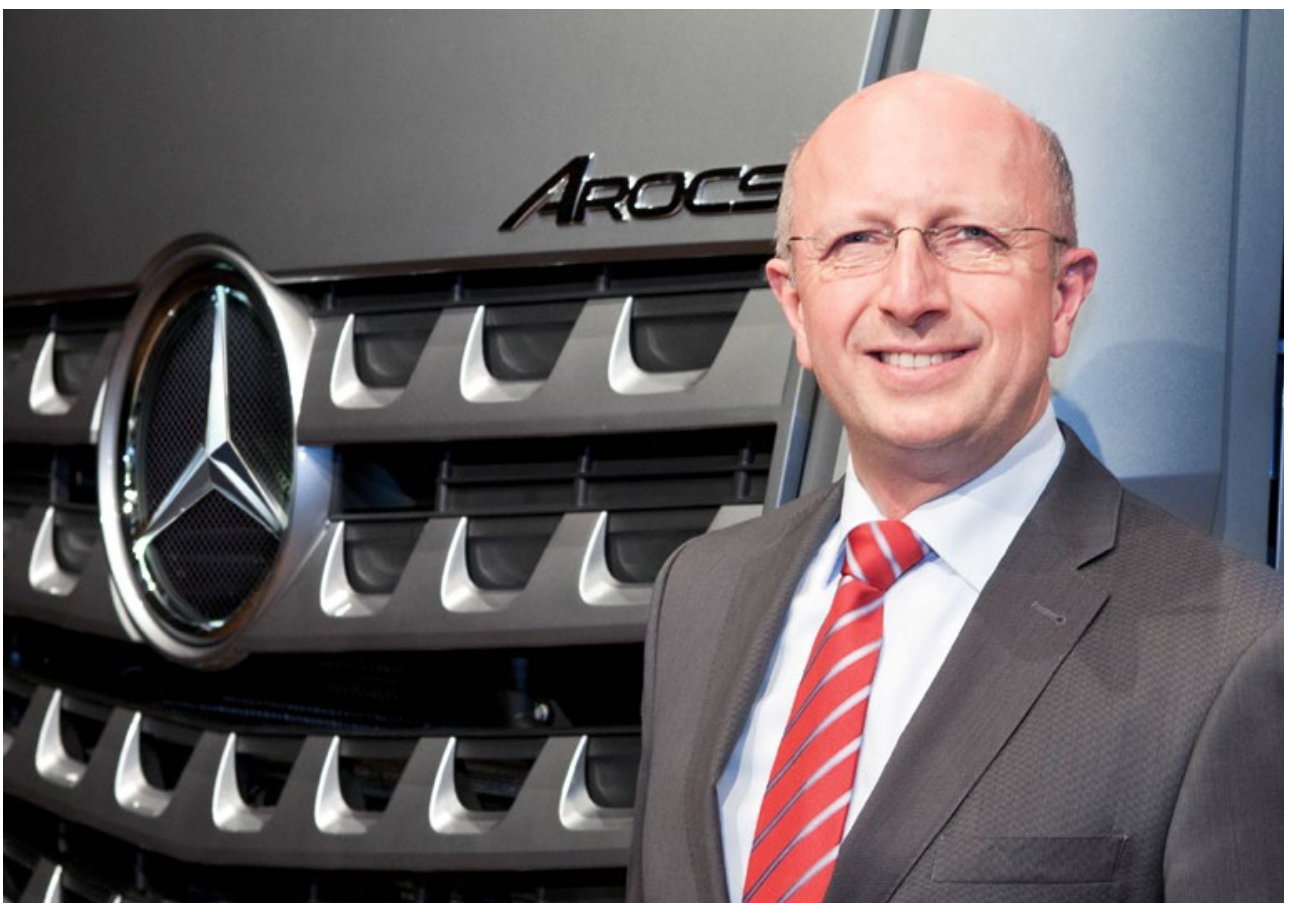

SVEN ENNERST

Trucks Product Engineering and Global Procurement, Daimler AG

\section{VERNETZTES DENKEN}

Der wichtigste Treiber in der Nutzfahrzeugentwicklung lässt sich mit drei Buchstaben zusammenfassen: TCO. Unsere Kunden müssen mit ihren Fahrzeugen Geld verdienen, deshalb sind optimale Total Cost of Ownership - also Gesamtbetriebskosten - für sie das Kaufargument schlechthin. Entsprechend haben wir bei Daimler Trucks seit jeher den Ehrgeiz, dass unsere Fahrzeuge in unseren Kernwerten Effizienz, Qualität und Sicherheit die technologische Speerspitze der Industrie bilden. Aus diesem Grund freue ich mich über meine neue Aufgabe als Entwicklungschef von Daimler Trucks, die für mich aufgrund der Vielfalt von Einsatzarten und Marktvorgaben zu den interessantesten Entwicklungsaufgaben überhaupt im Automobilbereich gehört.

Wozu unsere Ingenieure in der Lage sind, haben sie bei der Umsetzung der Euro-VI-Vorgaben gezeigt. Denken in ganzheitlichen neuen Fahrzeugkonzepten vom Antrieb bis hin zur Aerodynamik hat die Nachteile der aufwendigen Abgasreinigung aufgehoben: 5 \% Verbrauchsvorteil statt Mehrverbrauch das ist eine Meisterleistung. Insbesondere wenn man weiß, dass der Transporteur rund ein Drittel der Gesamtkosten an der Tankstelle ausgibt. Über 11.000 Mercedes-Benz-Lkw mit dieser Technologie bewähren sich auf der Straße.

Auf dem Erreichten können wir uns nicht ausruhen. Eine weitere Senkung von Verbrauch und $\mathrm{CO}_{2}$-Emissionen wird politisch diskutiert und liegt im wirtschaftlichen Interesse unserer Kunden. Hier sind intelligente Lösungen gefragt. Ein Beispiel ist die vorausschauende Steuerung des Antriebsstrangs, wie wir dies bei Mercedes-Benz mit Predictive Powertrain Control (PPC) auf die Straße gebracht haben. Damit fährt der Fahrer bei vergleichsweise geringen Anschaffungskosten nochmals bis zu $5 \%$ sparsamer. Weitere Potenziale müssen wir uns in Zukunft über die gesamte Bandbreite der Technologien erschließen: alternative Antriebe, alternative Kraftstoffe, gesamthafte Optimierung der Aerodynamik, neue Werkstoffe und vieles mehr. So hat Daimler Trucks beispielsweise kürzlich mit der Abgaswärmerückgewinnung ein Entwicklungsprojekt vorgestellt, von dem man sich weitere 3 bis $5 \%$ Effizienzsteigerung verspricht.

Wenn wir die anstehenden Entwicklungen höchst effizient vorantreiben wollen, dann werden wir noch stärker über den Globus hinweg vernetzt denken, zusammenarbeiten und weltweite Ressourcen intelligent nutzen müssen. Auf diese Weise können wir aus unserem globalen Portfolio bei Fahrzeugkonzepten, Komponenten und Technologien marktgerechte Angebote entwickeln und die TCO für unsere Kunden optimieren. Beispiel aus der jüngsten Vergangenheit sind die Euro-VIAntriebstechnologien bei Mercedes-Benz, die sich im Grundsatz schon vor Serieneinführung in Europa bei Freightliner in Amerika und bei Fuso in Japan bewährt haben. Oder auch die Sicherheitssysteme im Safety-Truck, den wir in ähnlicher Form auch in USA und in Japan haben. Die Aufgaben in der Nutzfahrzeugentwicklung bleiben spannend. Hier ist weiterhin Pioniergeist gefragt. Ich freue mich auf den Wettbewerb der Ideen. 